\title{
FREKUENSI LATIHAN SENAM YOGA MEMPENGARUHI PENINGKATAN FLEKSIBILITAS LUMBAL WANITA DEWASA DI KOTA DENPASAR
}

\author{
Cindy Anastasia Okhotan', I Dewa Ayu Inten Dwi Primayanti², Luh Made Indah Sri \\ Handari $^{2}$, I Putu Adiartha Griadhi ${ }^{3}$ \\ ${ }^{1}$ Program Studi Sarjana Kedokteran dan Profesi Dokter, Fakultas Kedokteran, Universitas \\ Udayana, Denpasar, Bali, Indonesia \\ ${ }^{2}$ Departemen Fisiologi, Fakultas Kedokteran, Universitas Udayana, Denpasar, Bali, \\ Indonesia
}

E-Mail: cindyanastasia26@gmail.com

\begin{abstract}
ABSTRAK
Latar Belakang: Penurunan fleksibilitas pada wanita dapat memicu terjadi nya penyakit, terutama keluhan muskuloskeletal yaitu cedera pada lumbal. Wanita dianjurkan untuk melakukan latihan-latihan sehingga dapat mencegah penurunan fleksibilitas. Tujuan: Mengetahui hubungan frekuensi senam yoga dengan fleksibilitas lumbal pada wanita. Metode: Penelitian observational analitik dengan pendekatan potong lintang yang menyertakan 45 wanita usia 20-45 tahun di Kota Denpasar. Sampel dipilah dengan teknik purposive sampling yang dilakukan pada empat studio senam yoga dan satu lapangan di Kota Denpasar selama bulan Juli - Agustus 2019. Data diperoleh dengan lembar pengumpulan data dan pengukuran fleksibilitas lumbal dengan sit and reach test. Data dianalisis dengan uji chi-square dan somers'd untuk mengetahui hubungan frekuensi senam yoga dengan fleksibilitas lumbal pada wanita. Hasil: Berdasarkan hasil uji, didapatkan nilai $\mathrm{p}=0,0001(\mathrm{p}<0,05)$ dan $\mathrm{r}=0,643(0,6 \leq \mathrm{r} \leq 0,8)$ memperlihatkan hubungan kuat dan bermakna antara frekuensi senam yoga dengan fleksibilitas lumbal pada wanita usia 20-45 tahun di Kota Denpasar. Kesimpulan: Terdapat hubungan signifikan antara frekuensi senam yoga dengan fleksibilitas lumbal ditandai dengan peningkatan nilai ukur fleksibilitas lumbal pada wanita dengan frekuensi senam yoga yang sangat rutin.
\end{abstract}

Kata kunci: Frekuensi senam yoga, Fleksibilitas lumbal, Senam yoga

\section{FREQUENCY OF YOGA EXERCISE IMPROVE ADULT WOMEN LUMBAR FLEXIBILITY IN DENPASAR CITY}

\section{ABSTRACT}

Background: Decreased flexibility in women can lead to injury, especially musculoskeletal disorder, namely lumbar injury. Women are encouraged to do exercises to prevent a decrease in flexibility. Aim: To find out the relation between yoga frequency and lumbar flexibility in women. Methods: This study was an observational analytic study with a cross-sectional approach involving 45 women aged 20-45 years in Denpasar City. Samples were selected using a purposive sampling technique conducted at four yoga gymnastics studios and a field in Denpasar from July - August 2019. Data were obtained with data collection sheets and measurement of lumbar flexibility using sit and reach tests. Data were analyzed with the chi-square test and somers'd to determine the relationship of the frequency of yoga exercises with lumbar flexibility in women. Results: Based on the test results, obtained $p=0.0001(p<0.05)$ and $r=0.643(0.6 \leq r \leq 0.8)$ which shows that there 
is a strong and significant relation between yoga frequency with lumbar flexibility in women aged 20-45 years in Denpasar City. Conclusions: There is a significant relationship between the frequency of yoga exercises with lumbar flexibility marked by an increase in the value of lumbar flexibility measurement in women with a very routine frequency of yoga exercises.

Keywords: Yoga frequency, Lumbar Flexibility, Yoga exercise

\section{PENDAHULUAN}

Setiap manusia memiliki berbagai kebutuhan dasar sehingga mendorong manusia untuk melakukan berbagai aktivitas tanpa rasa sakit. Fleksibilitas merupakan kemampuan sendi - sendi bergerak, dengan mudah, tanpa hambatan dan bebas dari rasa sakit, ${ }^{1}$ sehingga dengan kemampuan fleksibilitas yang baik seseorang dapat menjalankan berbagai kebutuhannya. Kemampuan fleksibilitas seseorang dapat menurun seiring dengan bertambahnya usia dikarenakan struktur otot dan jaringan yang berubah sehingga mengurangi elastisitas. ${ }^{2}$ Data di Amerika penelitian dari de Oliveira Medeiros dkk. pada tahun 2013 menunjukkan adanya penurunan fleksibilitas yang dramatis baik pria maupun wanita setelah usia 30 sampai 40 tahun. $^{3}$

Faktor lain yang mempengaruhi penurunan fleksibilitas selain faktor usia ialah faktor perbedaan jenis kelamin dan faktor aktivitas. Kemampuan fleksibilitas pada wanita akan menurun karena perbedaan hormon drastis terutama setelah menopause. ${ }^{4}$ Seseorang yang tidak aktif beraktivitas atau cenderung terus berada dalam keadaan diam, menyebabkan elastisitas otot berkurang. Jaringan dan sendi dapat menyusut dan kehilangan daya regangnya karena otot dipertahankan memendek terus-menerus dalam waktu lama. ${ }^{5}$

Beberapa kelainan yang sering muncul terkait dengan penurunan kemampuan fleksibilitas ialah keluhan muskuloskeletal, ${ }^{6}$ seperti cedera pada lumbal. ${ }^{7}$

Jenis latihan yang tepat untuk mencegah penurunan fleksibilitas ialah jenis latihan stretching. ${ }^{8}$ Stretching baik untuk fleksibilitas karena menguatkan otot yang lemah dan mencegah terjadinya ketegangan otot pada otot yang mudah kaku, sehingga dapat mempertahankan elastisitas otot. Otot yang telah disesuaikan dengan baik, akan mempengaruhi range of motion ligamen dan tendon, sehingga ligamen dan tendon dapat bekerja dengan tepat serta tidak mudah cedera. ${ }^{9}$ Stretching juga mempengaruhi persendian, karena dapat merangsang sekresi cairan sinovial sebagai cairan lubridikasi. Cairan ini dilepaskan ke dalam sendi untuk menjaga sendi tetap elastis, sehingga dapat mengurangi kekakuan. ${ }^{10}$

Yoga dapat menjadi pilihan stretching karena tampak aman, mudah dipelajari, tidak membutuhkan peralatan rumit, mahal maupun tempat latihan tertentu. Selain efek peningkatan fleksibilitas yang didapat, yoga juga memberikan berbagai manfaat lain seperti peningkatan kekuatan, keseimbangan, relaksasi dan perbaikan kualitas hidup. ${ }^{11}$ Studi tentang yoga, menyatakan subjek yang mengikuti kelas yoga selama dua kali seminggu dalam lima bulan pada 9 wanita berusia rata rata 23 tahun. Hasilnya terdapat peningkatan sebesar $6 \%$ sampai $8 \%$ pada fleksibilitas bahu, hip dan ankle. Selain itu terdapat juga peningkatan fleksibilitas thorakolumbal yang diukur dengan sit and reach test didapatkan peningkatan fleksibilitas sebanyak $2 \% .^{12}$

\section{METODE PENELITIAN}

Penelitian ini adalah penelitian analitik dengan metode potong lintang (cross sectional) dilaksanakan pada bulan Juli sampai Agustus 2019. Sampel yang digunakan ialah wanita yang bersedia menjadi responden penelitian dengan menandatangani informed consent dan telah memenuhi kriteria inklusi yaitu berusia 20 sampai 45 tahun, telah mengikuti latihan yoga rutin dalam kurun waktu minimal 8 minggu dan berkebangsaan Indonesia. Sedangkan kriteria 
eksklusi yaitu wanita tersebut mengikuti latihan fisik lain selain senam yoga secara teratur, mempunyai riwayat operasi pada bagian perut dan tulang belakang dalam kurun waktu 10 tahun, memiliki riwayat penyakit yang berhubungan dengan fleksibilitas lumbal seperti low back pain, faktur, tumor dan kelainan postur pada tulang belakang.

Pengambilan sampel dengan metode purposive sampling. Total sampel 45 orang pada empat studio dan satu lapangan di Kota Denpasar yaitu di Athaya Studio, Senam Bugar Citra, Mahaloka Yoga Studio, Yoga satu dan Kelompok Latihan Yoga di Lapangan Puputan Renon.

Pengumpulan data dimulai dengan perkenalan dan meminta persetujuan responden dengan penandatanganan informed consent, setelah itu responden mengisi kuesioner yang meliputi usia, pekerjaan, pendidikan, status perkawinan, tinggi badan, dan berat badan, riwayat cedera pada lumbal, frekuensi latihan, lama latihan, jenis dan durasi senam yoga. Peneliti kemudian melakukan pengambilan nilai fleksibilitas lumbal dengan sit and reach test.

\section{ANALISIS DATA}

Analisis data memakai perangkat lunak Statistical Package for the Social Science (SPSS). Analisis usia, pekerjaan, pendidikan, status perkawinan, tinggi badan dan berat badan menggunakan analisis deskriptif, diteruskan dengan melihat hubungan frekuensi senam yoga dan fleksibilitas lumbal menggunakan uji chisquare dan uji somers'd. Uji chi-square untuk melihat hasil secara statistik bermakna signifikan atau tidak ( $\mathrm{p} \leq 0,05)$, dan uji somers'd menunjukkan nilai koefisien korelasi (r) apabila nilai koefisien korelasi di antara $0,6 \leq \mathrm{r}<0,8$ maka menunjukkan hubungan yang kuat antara frekuensi senam yoga dengan fleksibilitas lumbal. Setelah itu dilanjutkan dengan uji yang sama antara hubungan variabel kontrol dengan fleksibilitas lumbal sehingga dapat diketahui pengaruhnya terhadap fleksibilitas lumbal.

\section{HASIL PENELITIAN}

\section{Karakteristik Responden Penelitian} Tabel 1.

Karakteristik Responden

\begin{tabular}{|c|c|c|}
\hline Karakteristik & $\mathrm{n}$ & Persentase (\%) \\
\hline \multicolumn{3}{|l|}{ Usia } \\
\hline 20-29 tahun & 13 & 28,9 \\
\hline 30-39 tahun & 9 & 20,0 \\
\hline 40-45 tahun & 23 & 51,1 \\
\hline \multicolumn{3}{|l|}{ Pekerjaan } \\
\hline BUMD & 1 & 2,2 \\
\hline Dokter & 3 & 6,7 \\
\hline Dokter gigi & 1 & 2,2 \\
\hline Ibu Rumah Tangga & 17 & 37,8 \\
\hline Karyawan Swasta & 20 & 44,4 \\
\hline Mahasiswi & 1 & 2,2 \\
\hline Pegawai Negeri & 1 & 2,2 \\
\hline Pelajar & 1 & 2,2 \\
\hline \multicolumn{3}{|l|}{ Pendidikan } \\
\hline Perguruan Tinggi & 38 & 84,4 \\
\hline SMA & 5 & 11,1 \\
\hline SMP & 2 & 4,4 \\
\hline \multicolumn{3}{|l|}{ Status Perkawinan } \\
\hline Belum menikah & 11 & 24,4 \\
\hline Janda & 2 & 4,4 \\
\hline Menikah & 32 & 71,1 \\
\hline \multicolumn{3}{|l|}{ Lama senam yoga } \\
\hline$<2$ tahun & 23 & 51,1 \\
\hline$>2$ tahun & 22 & 48,9 \\
\hline \multicolumn{3}{|l|}{ Jenis senam yoga } \\
\hline Postur & 26 & 57,8 \\
\hline Postur dan & 2 & 4,4 \\
\hline Meditasi & & \\
\hline Postur dan & 13 & 28,9 \\
\hline Pernafasan & & \\
\hline $\begin{array}{l}\text { Postur, Meditasi, } \\
\text { Pernafasan, } \\
\text { Filosophi }\end{array}$ & 4 & 8,9 \\
\hline
\end{tabular}

\section{Frekuensi senam \\ yoga}

\begin{tabular}{lcc} 
Jarang (1x) & 11 & 24,4 \\
Rutin (2-4x) & 26 & 57,8 \\
Sangat Rutin $(\geq 5 \mathrm{x})$ & 8 & 17,8 \\
\hline Fleksibilitas lumbal & & \\
Buruk & 11 & 24,4 \\
Cukup Baik & 9 & 20,0 \\
Baik & 9 & 20,0 \\
Sangat Baik & 7 & 15,6 \\
Sangat Baik Sekali & 9 & 20,0 \\
\hline
\end{tabular}


Tabel 1 memperlihatkan bahwa dari 45 orang wanita yang menjadi responden, ditemukan setengah dari total responden berusia usia antara 40-45 tahun (51,1\%), pekerjaan responden yang terbanyak ialah karyawan swasta $(44,4 \%)$, tingkat pendidikan terakhir responden yang terbanyak ialah perguruan tinggi $(84,4 \%)$, dan hampir tiga perempat dari total responden sudah menikah $(71,1 \%)$.

Tabel 1 juga menunjukkan jumlah responden yang berlatih kurang dari 2 tahun sama jumlahnya dengan yang lebih dari 2 tahun, dengan jenis latihan senam yang terbanyak ialah Yoga postur $(57,8)$.

Tabel 2.

Rerata Karakteristik Responden

\begin{tabular}{cc}
\hline Karakteristik & Rerata \\
\hline Tinggi & $160,42 \pm 5,42$ \\
Berat & $54,54 \pm 6,48$ \\
IMT & $21,19 \pm 2,34$ \\
\hline
\end{tabular}

Berdasarkan Tabel 2 rata - rata tinggi badan nya ialah $160 \mathrm{~cm}$, rata-rata berat badannya $54,5 \mathrm{~kg}$ dan rata-rata indeks massa tubuhnya ialah $21,19 \mathrm{~kg} / \mathrm{m} 2$.

\section{Uji Chi square}

\section{Tabel 3.}

Tabulasi silang frekuensi senam yoga dengan fleksibilitas lumbal

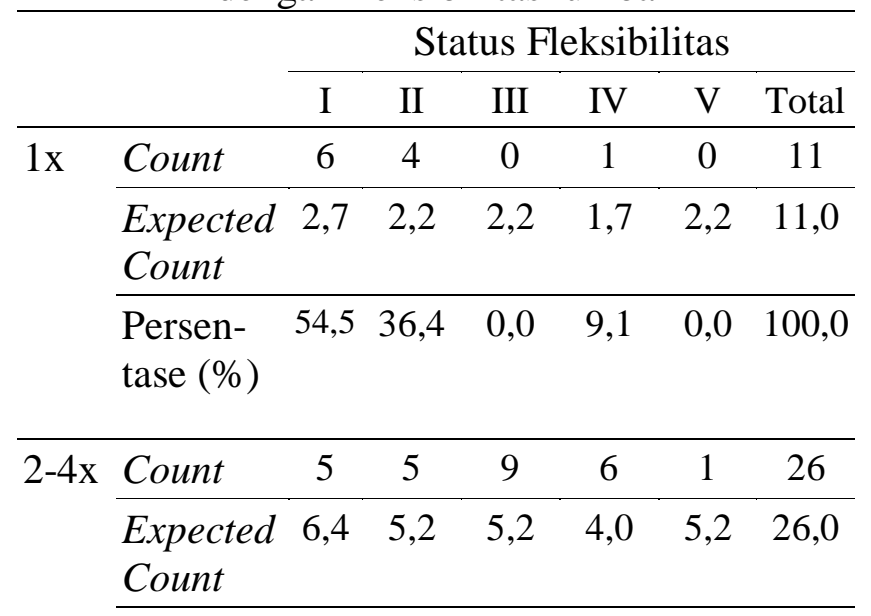

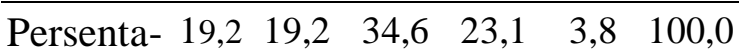
se $(\%)$

\begin{tabular}{llcccccc}
\hline$\geq 5 \mathrm{x}$ & Count & 0 & 0 & 0 & 0 & 8 & 8 \\
\cline { 2 - 7 } & $\begin{array}{l}\text { Expected } \\
\text { Count }\end{array}$ & 2,0 & 1,6 & 1,6 & 1,2 & 1,6 & 8,0 \\
\hline
\end{tabular}

$\begin{array}{lllllll}\text { Persenta- } & 0,0 & 0,0 & 0,0 & 0,0 & 100,0 & 100,0\end{array}$ se $(\%)$

\begin{tabular}{|c|c|c|c|c|c|c|}
\hline Total Count & 11 & 9 & 9 & 7 & 9 & 45 \\
\hline $\begin{array}{l}\text { Expected } \\
\text { Count }\end{array}$ & 11,0 & 9,0 & 9,0 & 7,0 & 9,0 & 45,0 \\
\hline $\begin{array}{l}\text { Persenta- } \\
\text { se }(\%)\end{array}$ & 24,4 & 20,0 & 20,0 & 15,6 & 20,0 & 100,0 \\
\hline
\end{tabular}

Tabel 4.

Chi square-test

\begin{tabular}{lcc}
\hline & $\begin{array}{l}\text { Fisher's } \\
\text { Exact value }\end{array}$ & P value \\
\hline Frekuensi & 35,058 & 0,000 \\
senam - & & \\
fleksibilitas & & \\
lumbal & & \\
\hline
\end{tabular}

Hasil uji chi-square memperlihatkan ho ditolak, nilai $\mathrm{p} \leq 0,05$ yaitu secara statistik ada hubungan signifikan antara frekuensi senam yoga dan fleksibilitas lumbal pada wanita usia 20- 45 tahun.

\section{Uji Somers'd}

Tabel 5.

Somers'd-test

\begin{tabular}{lcc}
\hline & $\begin{array}{l}\text { Somers'd } \\
\text { value }\end{array}$ & P value \\
\hline Frekuensi & 0,634 & 0,000
\end{tabular}

senam -

fleksibilitas

lumbal

Hasil uji somers'd menunjukkan nilai koefisien korelasi (r) di antara rentang $0,6 \leq \mathrm{r}$ $<0,8$ yang menunjukkan korelasi antara dua variabel yaitu frekuensi senam yoga dengan fleksibilitas kuat.

\section{Uji Kontrol Usia, Jenis Senam Yoga dan Lama Senam Yoga}

Tabel 6.

Chi square-test dan Phi-test pada variabel kontrol

\begin{tabular}{lccc}
\hline & $\begin{array}{c}\text { Person } \\
\text { Chi- } \\
\text { square }\end{array}$ & P value & $\begin{array}{c}\text { Phi } \\
\text { value }\end{array}$ \\
\hline Usia & 3,740 & 0,053 & 0,288 \\
\hline Lama senam & 26,546 & 0,000 & 0,606 \\
\hline Jenis senam & 0,114 & 0,736 & $-0,050$ \\
\hline
\end{tabular}


Pada uji kontrol, variabel dikelompokan berdasarkan kategorikal dikotomus agar tiap-tiap variabel setara untuk diuji. Variabel usia pada uji variabel kontrol dikategorikan menjadi usia dewasa awal yaitu rentang usia 20 - 39 tahun dan usia dewasa akhir yaitu 40 - 45 tahun. Hasil uji memperlihatkan nilai $\mathrm{p}>0,05$ yang memaparkan tidak adanya hubungan signifikan antara variabel usia dan fleksibilitas lumbal, serta koefisien korelasi (r) di antara rentang $0,2 \leq \mathrm{r}<0,4$ yang menunjukkan korelasi antara variabel usia dan fleksibilitas lumbal lemah.

Lama senam yoga dengan fleksibilitas lumbal menunjukkan nilai $\mathrm{p} \leq 0,05$, yang memperlihatkan ada hubungan signifikan antara variabel lama senam yoga dan fleksibilitas lumbal, serta koefisien korelasi (r) di antara rentang $0,6 \leq \mathrm{r}<0,8$ yang menunjukkan korelasi antara lama senam yoga dan fleksibilitas lumbal kuat.

Pada jenis senam yoga dikategorikan hanya menjadi jenis senam yoga postur dan jenis senam yoga postur beserta tambahan. Hasil uji memperlihatkan nilai $p>0,05$, yang berarti tidak ada hubungan signifikan antara jenis senam yoga dan fleksibilitas lumbal, serta koefisien korelasi (r) di antara rentang $0,0 \leq \mathrm{r}<0,2$ yang menunjukkan korelasi antara variabel jenis senam yoga dan fleksibilitas lumbal sangat lemah dan berlawanan arah

\section{PEMBAHASAN}

$\begin{array}{ccr}\text { Fleksibilitas lumbal, } & \text { selain } \\ \text { dipengaruhi aktivitas } & \text { latihan, } & \text { juga }\end{array}$ dipengaruhi oleh faktor internal dan eksternal lainnya. ${ }^{13}$ Faktor eksternal lainnya yaitu ukuran tubuh yaitu tinggi badan dan berat badan, cedera, usia dan jenis kelamin, untuk itu maka faktor-faktor lain ini telah didesain agar tidak memiliki perbedaan signifikan yang dapat mempengaruhi hasil penelitian dengan metode control by design (inklusi dan ekslusi) dan control by analysis.

Tabel 1 memperlihatkan distribusi frekuensi responden berdasarkan kelompok usia dewasa yaitu antara umur 20 sampai 45 tahun, ${ }^{14}$ antara kelompok umur 20 sampai 29 tahun, 30 sampai 39 tahun dan 40 sampai 45 tahun ini tentunya memiliki nilai patokan fleksibilitas lumbal yang berbeda, namun peneliti telah mendesain sesuai dengan acuan nilai dari American Collage of Sport Medicine $(\mathrm{ACSM})^{15}$ pada tiap- tiap kelompok umur sehingga usia bukanlah faktor perbedaan nilai fleksibiltas lumbal pada tiap-tiap kelompok usia ini.

Tabel 2 memperlihatkan rata-rata berat badan, tinggi badan dan Indeks Massa Tubuh responden penelitian. Rerata IMT sampel ialah 21,19 kg/m2. Menurut penelitian Paramurthi dkk, pada tahun 2015 yang dilakukan pada mahasiswa kedokteran, IMT berkorelasi postif dengan fleksibilitas lumbal diketahui dengan nilai $\mathrm{p}$ signifikan yaitu $\leq 0,05 .{ }^{16}$ Namun pada penelitian ini, IMT bukanlah faktor yang mempengaruhi nilai fleksibilitas lumbal dikarenakan seluruh responden memiliki IMT yang normal.

Pada penelitian ini responden diukur berdasarkan berapa kali responden tersebut melakukan yoga per minggunya. Yoga per minggu tersebut kemudian dikelompokan dalam tiga katergori yaitu kategori jarang (1x latihan), kategori rutin (2-4x latihan) dan kategori sangat rutin ( $\geq 5 x$ latihan). Durasi latihan responden berbeda-beda tergantung studio dan jenis yogas yang di jalani namun secara kesuluruhan berdurasi antara 60 - 90 menit. Sesi latihan senam yoga terdiri dari pemanasan dilanjutkan dengan postur fisik dan pengaturan pernafasan dan diakhiri oleh meditasi.

Berdasarkan hasil analisis data nilai fleksibilitas lumbal pada wanita usia 20-45 tahun yang mengikuti latihan senam yoga dengan frekuensi yang berbeda per minggu dengan uji chi-square dan somers'd ditemukan hubungan yang bermakna antara frekuensi senam yoga setiap minggu dengan fleksibilitas lumbal wanita yang menjadi responden penelitian.

Hasil penelitian ini sejalan dengan penelitian yang dilaksanakan pada sembilan wanita berusia 23,8 tahun yang diberikan latihan yoga selama dua kali seminggu selama lima bulan diketahui terdapat peningkatan 
fleksibilitas tulang belakang $14-20 \% .^{12}$ Penelitian lainnya yang dilaksanakan oleh Grabara dan Szopa juga memaparkan adanya hubungan latihan yoga dengan fleksibilitas lumbal pada wanita berusia 50 sampai 65 tahun yang diberikan latihan yoga 1 minggu sekali dengan durasi 90 menit selama 20 minggu diketahui dengan nilai $\mathrm{p} \leq 0,05,{ }^{17}$ dan pada penelitian yang dilakukan oleh Vitalistyawati, dkk. pada tahun 2018 yang membandingkan dua kelompok antara kelompok yang mendapat senam yoga dengan pilates juga memaparkan bahwa senam yoga dapat meningkatkan fleksibilitas lumbal pada wanita dewasa dengan nilai $\mathrm{p}<0,0001$, namun lebih kurang efektif bila dibandingkan dengan kelompok yang mendapat pilates. ${ }^{18}$

Sampai saat ini belum ada penelitian langsung yang menunjukkan hubungan frekuensi senam yoga yang berbeda setiap minggu terhadap fleksibilitas lumbal.

Berdasarkan kajian teori, hubungan bermakna antara frekuensi senam yoga setiap minggu dengan nilai fleksibilitas yang baik menjelaskan bahwa aktivitas atau latihan fisik terutama jenis latihan fisik peregangan (stretching) seperti senam yoga dapat mempengaruhi otot. Otot disusun oleh myofibril dan tiap myofibril dibangun dari unit kecil sarkomer yang teridiri dari myofilamen tipis dan tebal tumpang tindih dan bergerak bergesakan memperpendek panjang sarkomer yang disebut dengan sliding mechanism ketika otot berkontraksi. Myofibrils dapat berkontraksi, berelaksasi, dan memanjang. Senam yoga akan menyebabkan sarkomer memanjang, dan memicu berkurangnya sliding mechanism pada myofilamen. Hal ini akan menyebabkan otot menjadi memanjang. Ketika panjang sarkomer mencapai batasnya, maka ketegangan pada otot akan ditransmisikan ke tendon, sehingga tendon akan memanjang juga dan terjadi peningkatan range of motion. ${ }^{9}$

Terdapat juga saraf khusus pada otot yang disebut proprioceptor. Saraf ini akan berperan dalam stretching mechanism dengan menyampaikan informasi tentang sudut sendi, gerakan, dan perubahan dalam ketegangan otot. Proprioceptor yang pertama terletak di dekat ujung otot yaitu pada muscle spindle (reseptor peregangan) karena ketika otot meregang, maka muscle spindle yang trerletak di ujung otot juga akan ikut merenggang. Gerakan perenggangan yang diatur oleh proprioceptor pertama dikenal sebagai stretch reflex, yang mencegah terjadinya cedera oleh karena peregangan yang terlalu jauh, atau terlalu cepat. Ketika ketegangan dalam otot yang meregang mencapai batasnya maka akan ditransmisikan pada tendon, di sini terdapat proprioseptor ke dua yaitu organ tendon golgi yang befungsi untuk mentransmisikan sinyal ke tulang belakang sehingga memicu reaksi pemanjangan. Sinyal ini akan menghambat stretch reflex yang tadinya berkontraksi menjadi lebih relaks. ${ }^{9}$

Penelitian lainnya yang dikerjakan oleh Grabara tahun 2016 juga menjelaskan bahwa fleksibilitas lumbal dapat meningkat dikarenakan senam yoga postur terdapat gerakan backward bends yang dapat meningkatkan mobilitas antar tulang belakang, memperkuat otot-otot tulang belakang dan mencegah penyakit degeneratif terkait dengan penekanan pada diskus intervertebralis. Selain itu pada senam yoga postur terdapat juga gerakan torsion yang dapat menguatkan otot-otot oblique abdominal dan otot - otot pada punggung lainnya yang menyokong tulang belakang. ${ }^{19}$

Pada kelompok frekuensi senam yoga jarang (1x latihan perminggu), secara keseluruhan responden memiliki status fleksibilitas lumbal yang buruk dan cukup baik. Namun, pada kelompok frekuensi senam yoga rutin $(2-4 \mathrm{x}$ latihan perminggu) responden memiliki status fleksibilitas lumbal yang berbeda-beda. Hal ini dikarenakan pada kelompok ini terdapat responden yang telah mengikuti senam yoga lebih dari dua tahun dan ada responden yang kurang dari dua tahun sehingga menimbulkan hasil yang bervariasi. Sedangkan pada kelompok frekuensi senam yoga jarang dan sangat rutin ( $\geq 5 \mathrm{x}$ latihan perminggu) seluruh responden memiliki lama latihan senam yang sama yaitu pada kelompok jarang ialah kurang dari dua tahun dan pada kelompok sangat rutin lebih dari dua tahun. 
Hubungan lama senam yoga dengan fleksibilitas lumbal ini juga dibuktikan pada Tabel 5 yang memperlihatkan nilai $\mathrm{p} \leq 0,05$ dan koefisien antara $0,6 \leq \mathrm{r}<0,8$ yang menunjukkan hubungan kuat, akan tetapi pada penelitian ini, peneliti tidak membedakan sejak berapa lama responden telah mengikuti senam yoga dikarenakan keterbatasan waktu dan sampel penelitian. Variasi ini tentunya menjadi keterbatasan dalam penelitian ini.

\section{KETERBATASAN PENELITIAN}

Penelitian ini hanya menganalisis frekuensi senam yoga, dan tidak mengontrol sudah sejak berapa lama responden mengikuti pelatihan yoga. Variasi sampel dalam lama mengikuti pelatihan senam yoga ini tentunya juga berpengaruh terhadap hasil fleksibilitas lumbal, oleh karena itu perlu diadakan penelitian selanjutnya dengan kontrol juga terhadap lama sampel sudah mengikuti latihan senam yoga.

\section{SIMPULAN}

Berdasarkan penelitian yang telah dilaksanakan, disimpulkan terdapat hubungan kuat dan signifikan antara frekuensi senam yoga dengan fleksibilitas lumbal, namun terdapat juga pengaruh lama senam yoga terhadap fleksibilitas lumbal wanita usia 2045 tahun di Kota Denpasar.

\section{DAFTAR PUSTAKA}

1. Colby, J., Kisner, C. dan Allen, L. 2012. Therapeutic exercise: foundations and techniques. Edisi ke-6. United States of America : F.A. Davis Company Philadelphia.

2. Putra, F. P. 2014. Pengaruh Pemberian Streching terhadap Keluhan Musculoskeletal Bagian Bawah bagi Pekerja dengan Sikap Kerja Berdiri pada Bagian Winding di PT. Iskandar Indah Printing Textile Surakarta [skripsi].
Surakarta : Universitas Muhammadiyah Surakarta.

3. De Oliveira Medeiros, H. B., De Araújo, D. S. M. S. dan De Araújo, C. G. S. 2013. Age-related mobility loss is jointspecific: An analysis from 6,000 Flexitest results. Journal of the American Aging Association. Vol. 35. No. 6: 2399-407.

4. Susanti, S. D. 2012. Asuhan Kebidanan Kesehatan Reproduksi Pada Ny.S Umur 47 Tahun Dengan Menopause Di Puskesmas I Kembaran Kecamatan Kembaran Kabupaten Banyumas [skripsi]. Purwokerto : Universitas Muhammadiyah Purwokerto.

5. Seco, J., Abecia, L. C., Echevarria, E., dkk. 2013. A long-term physical activity training program increases strength and flexibility, and improves balance in older adults. Rehabilitation Nursing. Vol. 38. No. 1: 37-47.

6. Ulfah, N., Harwanti, S. dan Nurcahyo, P. J. 2014. Sikap Kerja dan Risiko Musculoskeletal Disorders pada Pekerja Laundry Work Attitude and Musculoskeletal Disorders Risk in Laundry Worker. Jurnal Kesehatan Masyarakat Nasional. Vol. 8. No. 7: 313-8.

7. Purepong, N., Jitvimonrat, A., Boonyong, S., dkk. 2012. Effect of flexibility exercise on lumbar angle: A study among non-specific low back pain patients. Journal of Bodywork \& Movement Therapies. Vol. 16. No. 2: 236-43.

8. Puspaningsih, I. A., Andayani N., Primayanti, I D. A. I. D., Sutadarma, I W. G. Perbedaan Efektifitas Intervensi Muscle Energy Technique dan Intervensi Active Isolated Stretching terhadap Peningkatan Fleksibilitas Otot Hamstring pada Pemain Sepak Bola Sman 1 Semarapura. Majalah Ilmiah Fisioterapi Indonesia. Vol. 5. No. 1: 20-23.

9. Harvard Medical School. 2014. Stretching: 35 stretches to improve flexibility and reduce pain. Boston.

10. Govindaraj, R., Karmani, S. dan Varambally, S. 2017. International 
Review of Psychiatry Yoga and physical exercise - a review and comparison. Journal International Review of Psychiatry. Vol. 28. No. 3: 242-53.

11. Kinasih, A. S. 2010. Pengaruh Latihan Yoga Terhadap Peningkatan Kualitas Hidup. Buletin Psikologi. Vol. 18. No. 1: $1-12$.

12. Petrič, M., Vauhnik, R. dan Jakovijevic, M. 2014. The Impact of Hatha Yoga Practice on Flexibility: A Pilot Study. Alternative \& Integrative Medicine. Vol. 3. No.2: 160-5.

13. Appleton, B. 1996. Stretching and Flexibility: Everything you never wanted to know. Serial online. [Cited 2019 Des 25]. Available from: URL: https://archive.org/details/Stretching_and _Flexibility_Brad_Appleton/page/n1.

14. Natari, D. A. M. 2016. Body Image Pada Wanita Usia Dewasa Awal yang Aktif Menggunakan Media Sosial di Kota Bandung [skripsi]. Bandung : Universitas Islam Bandung.

15. Pescatello, L. S., Arena, R., Riebe, D., dkk. 2014. ACSM's Guidelines for Exercise Testing and Prescription. 9th edn. Wolters Kluwer/Lippincott Williams \& Wilkins, Philadelphia, PA.

16. Paramurthi, I. A. P., Andayani, N., dan Purnawati, S. 2015. Hubungan antara Indeks Massa Tubuh dan Aktivitas Olahraga terhadap Fleksibilitas Lumbal pada Mahasiswa Fakultas Kedokteran Universitas Udayana. Majalah Ilmiah Fisioterapi Indonesia. Vol. 3. No. 1.

17. Grabara, M. dan Szopa, J. 2015. Effects of hatha yoga exercises on spine flexibility in women over 50 years old. Journal of physical therapy science. Vol. 27. No. 2: 361-5.

18. Vitalistyawati, L. P. A., Weta, I Wayan, Munawaroh, M., dkk. 2018. Pilates Exercise Lebih Efektif Meningkatkan Fleksibilitas Lumbal dibandingkan Senam Yoga pada Wanita Dewasa. Sport and Fitness Journal. Vol. 6. No. 2: 2330.

19. Grabara, M. 2016. Effects of hatha yoga exercises on spine flexibility in young adults. Biomedical Human Kinetics. Vol. 8. No. 1: 113-6. 